\title{
A Case of Rapid-onset Daptomycin-induced Neutropenia
}

\author{
Jason W. Lancaster ${ }^{1,2}$, Christine E. Vaudo ${ }^{1}$, Satinder P. Singh ${ }^{3}$ \\ ${ }^{1}$ Department of Pharmacy, Lahey Hospital \& Medical Center, Burlington, MA \\ ${ }^{2}$ Department of Pharmacy, Northeastern University, Boston, MA \\ ${ }^{3}$ Department of Hospital Medicine, Lahey Hospital \& Medical Center, Burlington, MA \\ Correspondence: Jason Lancaster (J.Lancaster@neu.edu)
}

Received August 12, 2016; accepted March 24, 2017

A 75-year-old Caucasian woman was transferred to a tertiary academic medical center for management of a foul smelling, non-draining, unstageable sacral pressure ulcer. Upon admission, the patient's laboratory data was notable for a white blood cell count (WBC) of 14.90 x $10^{-3} / \mu \mathrm{L}$ and absolute neutrophil count of $12.24 \times 10^{-3} / \mu \mathrm{L}$. After a complicated hospital course the patient was initiated on daptomycin $6 \mathrm{mg} / \mathrm{kg}(300 \mathrm{mg})$ daily in response to wound cultures detecting Enterococcus faecium susceptible only to daptomycin and linezolid. Starting 96 hours after daptomycin initiation, there was a profound reduction in the patient's WBC, reaching a nadir of $1.63 \times 10^{-3} / \mu \mathrm{L}$ after 12 days of therapy. Prior to documented resolution of her blood dyscrasia the patient was transferred to hospice care and use of antimicrobial therapy was withdrawn. The Naranjo Adverse Drug Reaction Probability Score demonstrated a probable relationship (score equal to 6) between daptomycin and the development of neutropenia. Unlike previous reports of daptomycin-induced neutropenia and/or thrombocytopenia, where patients received prolonged courses of daptomycin with doses ranging from $6-10 \mathrm{mg} / \mathrm{kg}$, this case describes a much more rapid onset of neutropenia that occurred at a dose of $6 \mathrm{mg} / \mathrm{kg} / \mathrm{day}$. This case reports highlights the risk for daptomycin to induce neutropenia in patients receiving traditional dosing, not just at higher doses, and within a shorter time-frame than previously documented. Healthcare providers should be cognizant of this adverse reaction, and diligent in monitoring for adverse events, associated with daptomycin use even when used for short courses or at traditional doses.

Keywords: daptomycin; Enterococcus; infectious diseases; neutropenia; thrombocytopenia.

\section{Introduction}

Neutropenia is defined as an overall reduction in the amount of neutrophils circulating within the body $^{1}$. The use of an absolute neutrophil count (ANC) is used to classify the level of neutropenia present, with the lower level set at $1500 \times 10^{-3} / \mu \mathrm{L}^{1}$. Mild neutropenia is defined by an ANC between $1000-1500 \times 10^{-3} / \mu \mathrm{L}$, moderate neutropenia and severe neutropenia are defined by ANCs of $500-1000 \times 10^{-3} / \mu \mathrm{L}$ and $<500 \times 10^{-3} / \mu \mathrm{L}$, respectively ${ }^{1}$. Initial symptoms of neutropenia often include new-onset infections coupled with fevers and malaise ${ }^{1}$. When patients develop neutropenia secondary to antibiotic use, such infections can be difficult to differentiate from a primary infection. 
The use of daptomycin, a cyclic lipopeptide antibacterial agent approved for use in the management of complicated skin and skin structure and Staphylococcus aureus bloodstream infections, has increased due to greater rates of drug-resistant gram-positive bacterial infections ${ }^{2}$. Despite being an appropriate agent for management of such drug-resistant gram-positive infections in neutropenic patients, several case reports describe the development of neutropenia or thrombocytopenia secondary to daptomycin use $\mathrm{s}^{3-6}$. We report a case of neutropenia attributed to the use of daptomycin in a patient with an Enterococcus faecium pressure ulcer.

\section{Case Presentation}

A 75-year old Caucasian female (height, $154.2 \mathrm{~cm}$, weight, $49.9 \mathrm{~kg}$ ) was transferred to a tertiary academic medical center from a rehabilitation facility for the management of new onset, foul smelling, non-draining, unstageable sacral pressure ulcer measuring 8 centimeters $x 7 \mathrm{~cm}$. The patient's past medical history was significant for a recent subdural hematoma, as well as a past cerebrovascular accident, dementia, essential hypertension, hyperlipidemia and type 2 diabetes mellitus. In the emergency department the patient was noted to have a maximum temperature of $39.1^{\circ} \mathrm{C}$, blood pressure of $126 / 68 \mathrm{mmHg}$, heart rate of 93/minute, and a respiratory rate of 20 with normal breath sounds. Baseline admission laboratory data was notable for a serum creatinine of $0.4 \mathrm{mg} / \mathrm{dL}$, calculated creatinine clearance of $112.4 \mathrm{~mL} / \mathrm{min}$ via the CockcroftGault equation, white blood cell (WBC) count of $14.90 \times 10^{-3} / \mu \mathrm{L}$ (baseline $8.3 \times 10^{-3} / \mu \mathrm{L}$ ), ANC of $12.24 \times 10^{-3} / \mu \mathrm{L}$ (baseline $5.83 \times 10^{-3} / \mu \mathrm{L}$ ), and a platelet count of $369 \times 10^{-3} / \mu \mathrm{L}$.

While in the emergency department the patient received a computed tomography scan of her head, chest, abdomen and pelvis which revealed a resolving bilateral subdural hematoma and a large pressure ulcer of the sacrum with edema extending into the coccyx and S5 vertebra concerning for osteomyelitis. Empiric therapy with intravenous (IV) cefepime $1000 \mathrm{mg}$ every 12 hours and IV vancomycin $1000 \mathrm{mg}$ every 12 hours was initiated after obtaining blood, stool, and urine cultures. Based on hospital dosing recommendations, a vancomycin trough was obtained prior the third dose on hospital day 2 , and returned at $9.7 \mu \mathrm{g} / \mathrm{mL}$, after which the vancomycin dose was changed to $1250 \mathrm{mg}$ every 12 hours; resulting in a trough level of $16.1 \mu \mathrm{g} / \mathrm{mL}$ which was drawn on hospital day 4 . By hospital day 5 all cultures were finalized and demonstrated no bacterial growth. The patient continued to have intermittent elevated temperatures during this time period (temperature maximum of $38.4^{\circ} \mathrm{C}$ ) but the WBC normalized to $7.96 \times 10^{-3} / \mu \mathrm{L}$. Vancomycin was discontinued on hospital day 5 and the patient remained on cefepime until hospital day 10 when it was discontinued by the hospital medicine team as the patient had remained afebrile for 72 hours combined with a lack of microbial presence within the culture data.

By hospital day 13 the patient's sacral pressure ulcer was reportedly improving, measuring 7 $\mathrm{cm} \times 6.5 \mathrm{~cm}$, and the patient was being prepared for discharge to a rehabilitation facility. But on the evening of hospital day 13 the patient became febrile with a rectal temperature of $38.8^{\circ} \mathrm{C}$, and laboratory data was notable for a WBC of $13.44 \times 10^{-3} / \mu \mathrm{L}$, ANC of $7.83 \times 10^{-3} / \mu \mathrm{L}$ and nonhighly sensitive C-reactive protein (CRP) of $231.4 \mathrm{mg} / \mathrm{L}$. Blood cultures were sent and the patient was re-initiated on IV cefepime (2000 mg every 12 hours due to a concern for hospitalacquired gram-negative organisms) and IV vancomycin (1000 mg every 12 hours). Over the next 5 days, hospital days 15-19, the patient remained on cefepime and vancomycin, was afebrile with the exception of two readings, both of $38.3^{\circ} \mathrm{C}$, on hospital days 16 and 17 , and a documented WBC within normal limits (range 6.88 to $10.2 \times 10^{-3} / \mu \mathrm{L}$ ). 
On hospital day 17 the patient was taken to the operating room for debridement of the pressure ulcer. Wound cultures grew Enterococcus faecium and Prevotella species on hospital day 20 and the patient's antibiotic regimen was changed from vancomycin and cefepime to IV daptomycin $300 \mathrm{mg}(6 \mathrm{mg} / \mathrm{kg})$ every 24 hours and IV ampicillin/sulbactam 3 grams every 6 hours.

Approximately 72 hours later, on hospital day 23, the E. faecium was noted to be resistant to ampicillin and vancomycin, with minimum inhibitory concentration $90 \%\left(\mathrm{MIC}_{90}\right)$ of $>8 \mu \mathrm{g} / \mathrm{mL}$ and $>16 \mu \mathrm{g} / \mathrm{mL}$, respectively). No further susceptibilities were reported for the Prevotella species. Ampicillin/sulbactam was discontinued, IV ertapenem $1000 \mathrm{mg}$ every 24 hours was initiated and daptomycin was continued. Ertapenem was continued for a total of 5 days, until hospital day 29, and daptomycin was continued until hospital day 38.

It was noted that, 48 hours after initiation of daptomycin (hospital day 22), the patient's WBC began to decline (Figure 1). The patient's WBC and ANC on hospital day 23 were reported to be $5.17 \times 10^{-3} / \mu \mathrm{L}$ and $0.27 \times 10^{-3} / \mu \mathrm{L}$, respectively. Ninety-six hours after initiation of daptomycin (hospital day 24), the patient's WBC underwent an approximate $45 \%$ reduction to $3.39 \times 10^{-3}$ $/ \mu \mathrm{L}$.

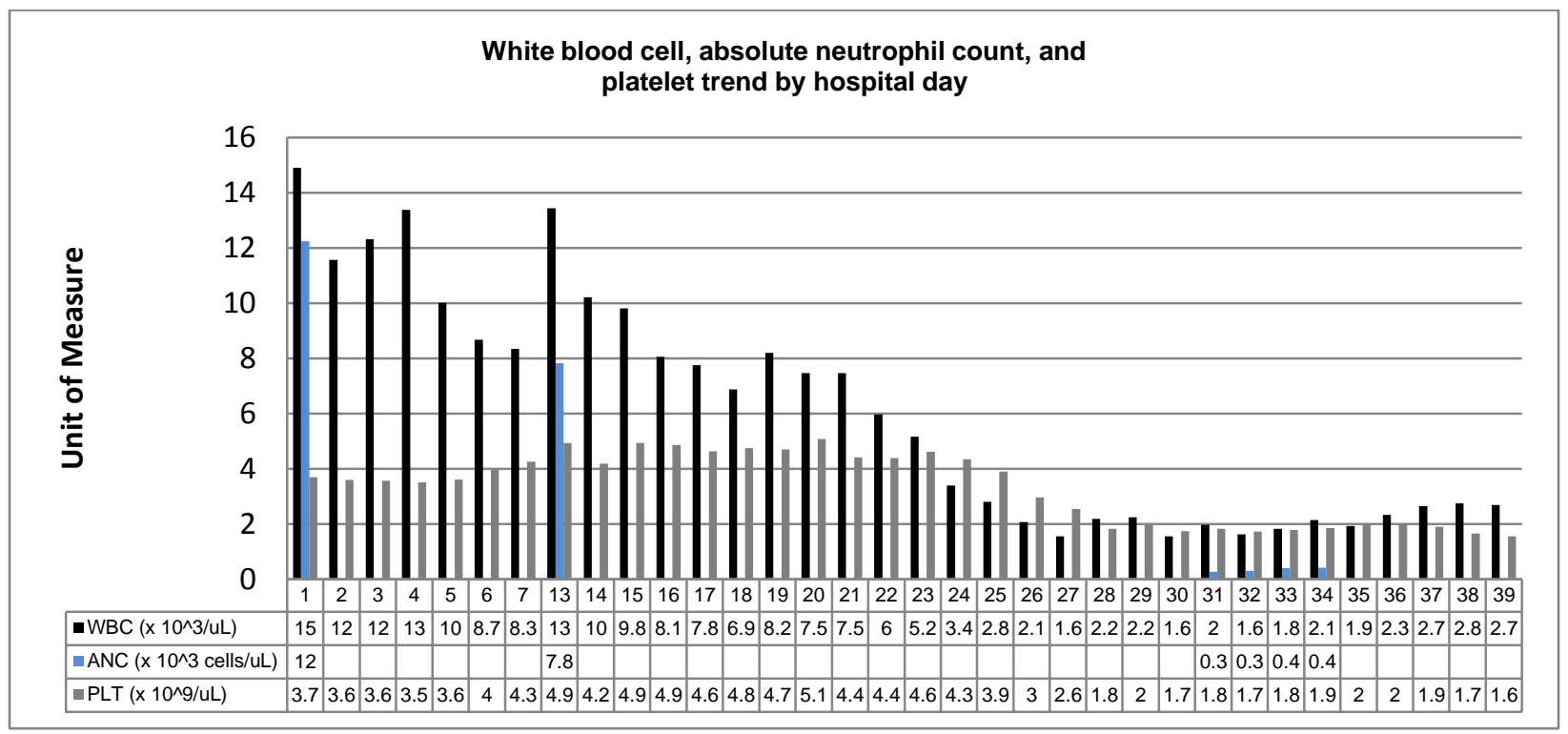

Figure 1. Trend in the patient's WBC, neutrophil and platelet counts over hospital days 13-39, with hospital days 1 and 7 included for baseline reference.

On hospital day 31 a workup began for neutropenia, including evaluation of drug-induced causes. Prior to this period of time, routine evaluation of the patient's ANC was not undertaken consistently. Other causes of neutropenia were ruled out via laboratory testing, including anemia, malignancy and vitamin deficiencies. Upon evaluation by Infectious Diseases, Hospital Medicine and Neurology services, neutropenia was suspected to be drug-induced. After thoroughly reviewing the patient's medication history, various agents were ruled out, specifically, the use of ampicillin/sulbactam, vancomycin and ertapenem were felt not to be contributory because the timeline of their use was not consistent with the onset of neutropenia and thrombocytopenia. Daptomycin was the only new agent identified during the time period when neutropenia and thrombocytopenia developed. When estimating the likelihood that the patient's neutropenia was 
a result of daptomycin use, the Naranjo Adverse Drug Reaction Probability Score demonstrated a probable relationship (score equal to 6$)^{7}$. This score was calculated based on the presence of previous case reports supporting this reaction $(+1)$, the presence of a sustained decrease in WBC count after initiation of daptomycin $(+2)$, a lack of likely alternate causes $(+2)$, and confirmation of the reaction was based on objective evidence $(+1)$. When evaluating other potential medication-causes of this reaction, the use of alternative antibiotics did not generate a Naranjo score as high as that calculated for daptomycin, largely based on the lack of persistent reductions in WBC count and/or platelet counts during treatment.

The patient's WBC and ANC reached a nadir on hospital days 32 and 33 with a value of $1.63 \mathrm{x}$ $10^{-3} / \mu \mathrm{L}$ and $0.27 \times 10^{-3} / \mu \mathrm{L}$, respectively. On hospital day 38 the patient requested withdrawal of care due to a concern for treatment futility. Subsequently, all antibiotic therapy was discontinued and laboratory monitoring ceased. The patient transitioned to target comfort measures only and she was transferred to a healthcare facility closer to her home. Confirmatory testing using Immunoglobulin ( $\mathrm{Ig}$ ) $\mathrm{G}$ antiplatelet antibodies was not done due to non-availability.

\section{Discussion}

Drug-induced neutropenia has been attributed to a number of pharmacologic agents, including antibacterial agents. Of the eleven agents accounting for greater than fifty percent of all reported cases of drug-induced neutropenia, the use of penicillin, trimethoprim-sulfamethoxazole and dapsone rank amongst the most likely agents to induce neutropenia ${ }^{8,9}$. The development of neutropenia by these agents has been proposed to include both immunologic and nonimmunologic, or cytotoxic, mechanisms. However, specifics surrounding these mechanisms are lacking within the literature. From the published literature surrounding the use of daptomycin, there have been three published case reports to date, implicating its use in the development of neutropenia and/or thrombocytopenia.

Knoll and colleagues described their findings from a 53-year-old woman diagnosed with B-cell non-Hodgkin lymphoma who, after 10 weeks of daptomycin therapy at $6 \mathrm{mg} / \mathrm{kg} / \mathrm{day}$, developed neutropenia ${ }^{3}$. At that time the patient's WBC and ANC were reported to be $1.6 \times 10^{-3} / \mu \mathrm{L}$ and 0.8 $\mathrm{x} 10^{-3} / \mu \mathrm{L}$, with no reported change in her platelet count. Upon discontinuation of daptomycin, the patient had resolution of her neutropenia with a reported $\mathrm{WBC}$ of $5 \times 10^{-3} / \mu \mathrm{L}$ and an ANC of $3.4 \times 10^{-3} / \mu \mathrm{L}$. Furthermore, Leyra and colleagues described a case of a 75-year-old woman who developed both neutropenia and thrombocytopenia associated with prolonged, high dose daptomycin $(10 \mathrm{mg} / \mathrm{kg} / \mathrm{day})$ in the management of endocarditis ${ }^{4}$. This patient developed her blood dyscrasias on the $28^{\text {th }}$ day of daptomycin and cefepime therapy. After discontinuation of cefepime on the $35^{\text {th }}$ day and daptomycin on the $38^{\text {th }}$ day the WBC and platelet counts normalized, after reaching a nadir of $2.2 \times 10^{-3} / \mu \mathrm{L}$ and $0.04 \times 10^{-3} / \mu \mathrm{L}$, respectively. After a total intensive care unit stay of 64 days the patient was deemed stable enough to be transferred to the medical floor.

In a separate case, Gregoire and colleagues described a 64-year-old man admitted to an intensive care unit who received daptomycin $6 \mathrm{mg} / \mathrm{kg} / \mathrm{day}$, in addition to other targeted agents, for an abdominal abscess positive for Staphylococcus epidermidis, Enterococcus faecalis and Pseudomonas aeruginosa ${ }^{5}$. After four days of therapy the patient developed extensive purpura and a reported platelet count of less than $0.01 \times 10^{-3} / \mu \mathrm{L}$. Subsequently, the patient died secondary to a brain herniation. Additionally, Hartmann and colleagues described another case of thrombocytopenia attributed to daptomycin ${ }^{6}$. In this case a patient with $S$. epidermidis bacteremia 
developed thrombocytopenia, with a platelet count of $5.2 \times 10^{-3} / \mu \mathrm{L}$, after receiving 6 weeks of daptomycin at a dose of $6 \mathrm{mg} / \mathrm{kg} /$ three times weekly dose reduced for dialysis. Table 1

summarizes each of the published case reports outlined above. Lastly, various mechanisms evaluated by the authors of the above referenced case reports have been explained in these case reports. Gregorie and colleagues found a high presence of megakaryocytes in a bone marrow aspirate of their patient, which they attributed to the breakdown of circulating platelets, as well as daptomycin-specific antibodies bound to platelets via flow-cytometry, indicating an immunemediated mechanism behind the development of thrombocytopenia.

Table 1. Summary of published case reports on daptomycin related neutropenia and/or thrombocytopenia

\begin{tabular}{|c|c|c|c|c|c|c|}
\hline $\begin{array}{c}\text { Reference } \\
\text { number }\end{array}$ & Patient data & $\begin{array}{l}\text { Rationale for } \\
\text { daptomycin } \\
\text { use }\end{array}$ & $\begin{array}{l}\text { Daptomycin } \\
\text { dose }\end{array}$ & $\begin{array}{l}\text { Timeline of onset of } \\
\text { blood dyscrasias } \\
\text { after daptomycin } \\
\text { initiation (days) }\end{array}$ & $\begin{array}{l}\text { Type of blood } \\
\text { dyscrasias and } \\
\text { severity }\end{array}$ & Outcome \\
\hline 3 & $\begin{array}{l}53 \text { year old } \\
\text { woman with } \\
\text { B-cell non- } \\
\text { Hodgkin } \\
\text { lymphoma }\end{array}$ & $\begin{array}{l}\text { Methicillin- } \\
\text { resistant } S \text {. } \\
\text { aureus septic } \\
\text { arthritis not } \\
\text { responding to } \\
11 \text { weeks of } \\
\text { intravenous } \\
\text { vancomycin } \\
\text { therapy }\end{array}$ & $6 \mathrm{mg} / \mathrm{kg} /$ day & 70 & $\begin{array}{l}\text { Neutropenia only. } \\
\text { Baseline: WBC / } \\
\text { ANC was } 5.6 \times 10^{-} \\
3 / \mu \mathrm{L} \text { and } 4.1 \times 10^{-} \\
3 / \mu \mathrm{L} \\
\text { Nadir: } \mathrm{WBC} / \mathrm{ANC} \\
\text { was } 1.6 \times 10^{-3} / \mu \mathrm{L} \\
\text { and } \\
0.8 \times 10^{-3} / \mu \mathrm{L}\end{array}$ & $\begin{array}{l}\text { Resolution of } \\
\text { neutropenia } 7 \\
\text { days after drug } \\
\text { discontinuation. }\end{array}$ \\
\hline 4 & $\begin{array}{l}75 \text { year old } \\
\text { woman } \\
\text { undergoing } \\
\text { bio- } \\
\text { prosthetic } \\
\text { mitral valve } \\
\text { surgery }\end{array}$ & $\begin{array}{l}\text { Empiric } \\
\text { management of } \\
\text { new-onset } \\
\text { malaise, fever } \\
\text { and dyspnea } \\
\text { approximately } \\
\text { one month } \\
\text { after surgery }\end{array}$ & $\begin{array}{l}10 \\
\mathrm{mg} / \mathrm{kg} / \mathrm{day}\end{array}$ & $\begin{array}{l}33 \\
\text { (thrombocytopenia) } \\
\text { 41(neutropenia) }\end{array}$ & $\begin{array}{l}\text { Thrombocytopenia } \\
\text { (day } 33 \text { ), and } \\
\text { neutropenia (day } \\
41 \text { ). } \\
\text { Platelet count on } \\
\text { day } 28 \text { was } 200 \times \\
10^{-3} / \mu \mathrm{L} \text {. } \\
\text { Nadir: Platelet count } \\
27 \times 10^{-3} / \mu \mathrm{L}, \text { ANC } \\
0.07 \times 10^{-3} / \mu \mathrm{L} \text {. }\end{array}$ & $\begin{array}{l}\text { Transferred to } \\
\text { the medical floor } \\
\text { after } 64 \text { days in } \\
\text { intensive care. }\end{array}$ \\
\hline 5 & $\begin{array}{l}64 \text { year old } \\
\text { man } \\
\text { admitted to } \\
\text { an } \\
\text { intensive- } \\
\text { care unit }\end{array}$ & $\begin{array}{l}\text { Polymicrobial } \\
\text { abdominal } \\
\text { abscess, } \\
\text { including } E \text {. } \\
\text { faecalis }\end{array}$ & $6 \mathrm{mg} / \mathrm{kg} /$ day & 4 & $\begin{array}{l}\text { Thrombocytopenia } \\
\text { only. } \\
\text { No baseline platelet } \\
\text { count reported, but } \\
\text { count after } 4 \text { days of } \\
\text { therapy was } \\
<10 \times 10^{-3} / \mu \mathrm{L} \text {. }\end{array}$ & Died \\
\hline 6 & $\begin{array}{l}61 \text { year old } \\
\text { man on } \\
\text { dialysis }\end{array}$ & $\begin{array}{l}\text { S. epidermidis } \\
\text { bacteremia }\end{array}$ & $\begin{array}{l}6 \\
\mathrm{mg} / \mathrm{kg} / \text { three } \\
\text { times } \\
\text { weekly }\end{array}$ & 42 & $\begin{array}{l}\text { Thrombocytopenia } \\
\text { only. } \\
\text { No baseline platelet } \\
\text { count reported, but } \\
\text { count after } 42 \text { days } \\
\text { of therapy was } \\
52 \times 10^{-3} / \mu \mathrm{L} \text {. }\end{array}$ & $\begin{array}{l}\text { Antibiotic } \\
\text { regimen was } \\
\text { discontinued but } \\
5 \text { weeks later } \\
\text { patient sustained } \\
\text { a cardiac arrest } \\
\text { and died. }\end{array}$ \\
\hline
\end{tabular}

While there are similarities between our case and those in the published literature, there are distinct differences that are worth highlighting. First, our patient, like the case report by Leyra and colleagues developed both neutropenia and a thrombocytopenia rapidly after initiation of daptomycin. However, the dose of daptomycin used was lower in our patient, i.e $6 \mathrm{mg} / \mathrm{kg} / \mathrm{day}$ 
versus $10 \mathrm{mg} / \mathrm{kg} /$ day. Unlike the other cases, our patient developed her blood dyscrasias much more rapidly.

In conclusion, our case adds to the existing literature surrounding the development of neutropenia and thrombocytopenia with the use of daptomycin. Furthermore, it demonstrates that such blood dyscrasia can occur even at lower doses, and with shorter courses of therapy, than previously noted in the literature.

\section{Notes}

Author contributions: All authors have seen and approved the manuscript, and contributed significantly to the work.

Financial support: Authors declare that no financial assistance was taken from any source.

Potential conflicts of interest: Authors declare no conflicts of interest. Authors declare that they have no commercial or proprietary interest in any drug, device, or equipment mentioned in the submitted article.

\section{References:}

1. Watts RG. Neutropenia. In: Lee GR, Foerster J, Lukens J, et al, editors. Wintrobe's Clinical Hematology. 10th ed. Baltimore, Md: Lippincott, Williams \& Wilkins; 1999: 1862-1888.

2. Daptomycin (Cubicin) package insert. Lexington, MA: Cubist; 2015 Nov.

3. Knoll BM, Spieler PJ, Kubiak DW, Marty FM. Neutropenia associated with prolonged daptomycin use. Clin Infect Dis. 2013;56:1353-1354.

4. Leyra F, Perez-Chulia N, Jofre C et al. Thrombocytopaenia and neutropaenia associated with daptomycin use. J Chemother. 2015;Epub ahead of print.

5. Gregoire C, Brumpt $\mathrm{C}$, Loirat $\mathrm{D}$ et al. A case of daptomycin-induced immune thrombocytopenia. Antimicrob Agents Chemother. 2012;56:6430-6431.

6. Hartmann B, Maus S, Keller F, Rothermund L. Thrombocytopenia, INR prolongation and fall in fibrinogen under daptomycin. J Chemother. 2011;23(3):183-184.

7. Naranjo CA, Busto U, Sellers EM et al. A method for estimating the probability of adverse drug reactions. Clin Pharmacol Ther. 1981;30:239-45.

8. Rolston KV, Besece D, Lamp KC et al. Daptomycin use in neutropenic patients with documented gram-positive infections. Support Care Cancer. 2014;22:7-14.

9. Andersohn F, Konzen C, Garbe E. Systematic review: agranulocytosis induced by nonchemotherapy drugs. Ann Intern Med. 2007;146(9):657-65. 